\title{
Analyses of Microarc Oxidation Coatings Formed on Si- containing Cast Aluminum Alloy in Silicate Solution
}

\author{
Wenbin XUE, Chao WANG, Yongliang LI, ${ }^{1)}$ Ruyi CHEN and Tonghe ZHANG \\ Key Laboratory for Radiation Beam Technology and Materials Modification, Institute of Low Energy Nuclear Physics, Beijing \\ Normal University, Beijing, 100875, China. 1) Analytical and Testing Center, Beijing Normal University, Beijing, 100875, \\ China. E-mail: xuewb@263.net
}

(Received on May 13, 2002; accepted in final form on July 7, 2002)

\begin{abstract}
A dense ceramic coating up to $130 \mu$ m thick was deposited on high silicon cast aluminum alloy by microarc discharge in silicate electrolyte. Its microstructure and composition were analyzed by scanning electron microscopy (SEM) with energy dispersive spectroscopy (EDS), and phase identification was performed by $\mathrm{X}$-ray diffraction (XRD). In addition, the distributions of hardness, $\mathrm{H}$, and elastic modulus, $\mathrm{E}$, across the ceramic coating were determined by nanoindentation method. The coating has a three-layer structure. The profiles of $\mathrm{H}$ and $\mathrm{E}$ in the coating are similar. From the surface to the inner layer of the coating, $\mathrm{H}$ and $\mathrm{E}$ gradually increase. The inner layer is dense and hard, in which the $\mathrm{H}$ and $\mathrm{E}$ can reach about $15 \mathrm{GPa}$ and 250 $\mathrm{GPa}$, respectively. This coating consists of mullite, $\gamma-\mathrm{Al}_{2} \mathrm{O}_{3}, \gamma-\mathrm{Al}_{2} \mathrm{O}_{3}$ and amorphous $\mathrm{SiO}_{2}$ phases. The surface layer enriched in $\mathrm{Si}$ element has a high fraction of amorphous $\mathrm{SiO}_{2}$, where the Si element comes mainly from the electrolyte rather than the alloy substrate. However, the Si element from Al-Si substrate enhances the formation of mullite phase in the coating.
\end{abstract}

KEY WORDS: microarc oxidation; AI-Si alloy; ceramic coating.

\section{Introduction}

Al-Si cast alloys have become more widely used in automobile and aerospace industry due to their excellent properties, such as high strength to density ratio, high castability and machinability. However, their wear resistance and corrosion resistance are poor. For certain applications, Al-Si alloys may need protective coatings. Anodic oxidation has been the primary process to form protective films on aluminum components. Nevertheless, it is difficult to obtain a thick and dense anodic film on Si-containing cast aluminum alloys due to the hindrance of Si species on film growth.

Microarc oxidation (MAO) is a potential process to synthesize the ceramic-like oxide coatings on valve metals such as $\mathrm{Al}, \mathrm{Mg}, \mathrm{Ti}^{1}{ }^{1-9)}$ It derives from anodic oxidation, but its applied voltage can reach several hundred volts. During oxidation, many visible sparks or microarcs move quickly on the surface of metals. This process combines electrochemical oxidation with a high voltage spark sintering in an electrolyte bath. Complex compounds are synthesized inside microplasma discharge channels across the oxide layer. Specifically, the MAO method can fabricate thick ceramic coatings on cast aluminum alloys containing higher silicon content.

Microarc oxidation treatment on $\mathrm{Al}-\mathrm{Cu}$ alloys has been studied in detail. ${ }^{9-14)}$ The corresponding investigation on $\mathrm{Al}-\mathrm{Si}$ alloys is much less. In particular, the influence of the Si element on microstructure and composition of the MAO coatings is rarely considered. In present paper, a ceramic coating on ZL101 Al-Si cast alloy was prepared by microarc discharge in silicate electrolyte. Its microstructure and phase constituent were analyzed. The hardness and elastic modulus profiles of the coating were determined. Furthermore, the influence of the Si element on microstructure and properties was discussed.

\section{Experimental Procedure}

Rectangular coupons $(50 \mathrm{~mm} \times 30 \mathrm{~mm} \times 8 \mathrm{~mm})$ of ZL101 cast aluminum alloy were used as substrate for coating deposition; the nominal composition of this alloy is $6.5-7.5 \%$ $\mathrm{Si}, 0.25-0.45 \% \mathrm{Mn}$ and Al balance. They were ground by $600 \#$ paper and washed with distilled water. The coatings were fabricated using an alternating-current microarc oxidation system which we have described previously. ${ }^{4,14)}$ In the oxidation process, the optimal deposition parameters described in our previous study ${ }^{14)}$ were used in the present work. The applied potential was in the range of 400-600 V, and the current density was about $15 \mathrm{~A} / \mathrm{dm}^{2}$. An electrolyte was prepared from a conventional MAO solution of sodium silicate $(6 \mathrm{~g} / l)$ in distilled water with addition of $\mathrm{KOH}(1-2$ $\mathrm{g} / l)$ to adjust $\mathrm{pH}$ and conductivity. The electrolyte was cooled to remain lower than $35^{\circ} \mathrm{C}$ during the entire treatment procedure. The oxidation time is $5 \mathrm{~h}$.

The as-deposited coating is $130 \mu \mathrm{m}$ thick, which is nondestructively determined by eddy current technique. After this coating was ground with $\mathrm{SiC}$ paper, a dense layer of about $80 \mu \mathrm{m}$ was left. A DMAX-3A X-ray diffractometer 
( $\mathrm{Cu} \mathrm{K} \alpha$ radiation) was used to investigate the phase constituents of polished and unpolished coated samples. The microstructures of the surface and cross-section of the coating were observed using OPTON CSM 950 scanning electron microscope. An EDS attachment was used to analyze the chemical composition of the coating and alloy substrate. In addition, hardness and elastic modulus profiles of a cross-sectional coated sample were performed by nanoindention method (Nano Indenter II manufactured by Nano Instruments, Inc.). The load and displacement resolutions are $75 \mathrm{nN}$ and $0.04 \mathrm{~nm}$, respectively.

\section{Experimental Results}

\subsection{SEM and EDS Analyses of the MAO Coatings}

A typical microstructure of ZL101 Al-Si cast alloy is shown in Fig. 1. The alloy contains $\mathrm{Al}, \mathrm{Si}$ and $\mathrm{FeSiAl}_{5}$ phases. The grey-white net-like structure is Al-Si eutectic area. In addition, few white needle-like $\mathrm{FeSiAl}_{5}$ particles appear in the Al-Si eutectic area.

As shown in Fig. 2(a), the coating surface on Al-Si alloy is rather rough and contains many grains with various sizes, which is similar to the coating morphology formed on Al$\mathrm{Cu}$ Alloy. ${ }^{14)}$ There are also many small pores on the surface, which correspond to the spark or microarc discharge channels. These pores are only as deep as several microns and do not penetrate the whole coating. Figure 2(b) indicates a magnified grain which center has a pore of $2 \mu \mathrm{m}$ diameter. While the melt erupts from the discharge channel, one part of the erupted melt rapidly deposits on the surface around

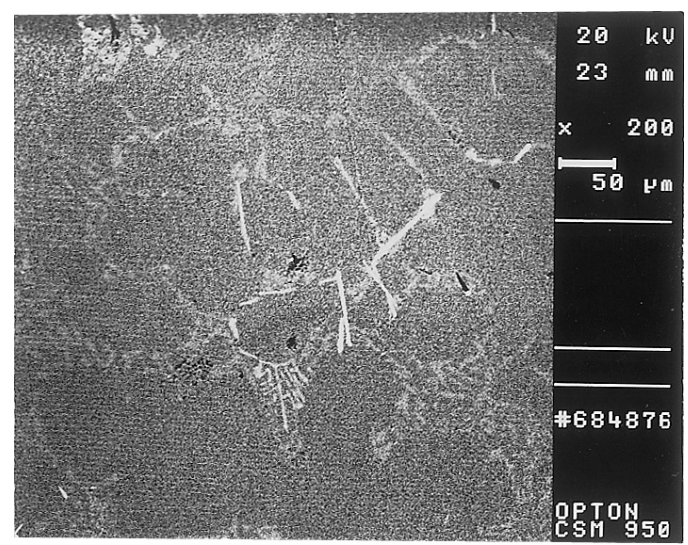

Fig. 1. Microstructure of ZL101 Al-Si cast alloy.

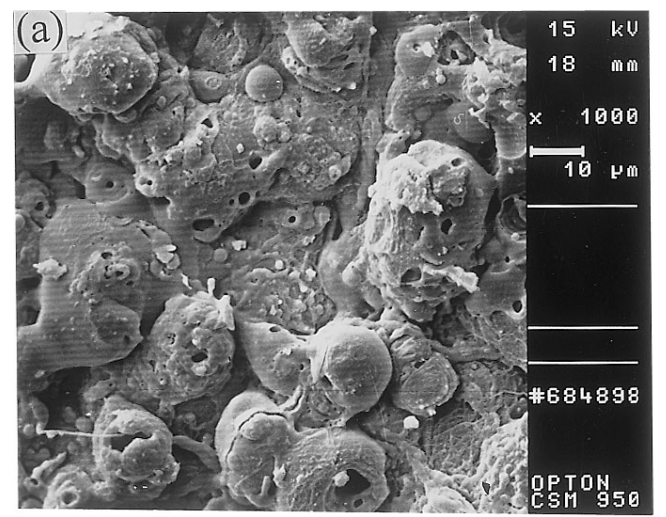

this pore due to the solution cooling. The molten trace on the coating surface is clearly observed.

The cross-sectional micrographs of the MAO coating on ZL101 Al-Si alloy are displayed in Fig. 3. There are not larger voids near the coating/alloy interface. It shows a good metallurgical adhesion between the coating and Al-Si substrate. Furthermore, the heat affected zone in the Al-Si substrate near the interface can not be found. That proves that the temperature of alloy substrate during oxidation is lower, and high-temperature and high-pressure process in microarc discharge channel has hardly influence on the remained alloy substrate.

$\mathrm{Al}, \mathrm{O}$ and Si line scans across the coating and alloy substrate (see Figs. 3(a) and 3(b)) indicate that this MAO coating consists of three layers. The inner layer of $70 \mu \mathrm{m}$ thick is rather dense, where the $\mathrm{Si}$ and $\mathrm{O}$ element contents are low. However, the intermediate layer of about $40 \mu \mathrm{m}$ thick has some isolated pores. The surface layer of the coating is not uniform and its thickness is in a range of $10-30 \mu \mathrm{m}$. In the surface layer, Al content is low but $\mathrm{Si}$ content is much high. However, the Si and $\mathrm{O}$ element contents in the intermediate layer and surface layer are much higher than in the inner layer. That implies that the Si element in the outer layer mainly comes from the silicate solution rather than the Al-Si alloy substrate. Therefore, the electrolytic ions have incorporated into the whole coating, and enrich in the outer layer of the coating.

Figures 3(c) and 3(d) are SEM backscattered electron images near the coating/alloy interface. The contrast at two sides of the interface is high, which reflects the average atomic number of the alloy substrate is higher than that of the oxide coating. Oxygen scanning line in Fig. 3(c) shows that oxygen does not diffuse into the remained Al-Si substrate, even near the coating/alloy interface. Although the atomic numbers of $\mathrm{Al}$ and $\mathrm{Si}$ elements have a little difference, a grey-white Si particle referred by arrow A in Fig. 3(c) appears in the alloy near the interface. The Si line analysis (see Fig. 3(d)) shows that one part of elemental Si particle at the interface has been oxidized into the coating, however, Si content near this silicon particle is higher than other part of the coating. Furthermore, a very bright needlelike particle referred by arrow B also presents in the alloy near the interface. EDS analysis identifies that this needlelike particle is Fe rich phase as same as shown in Fig. 1.

After the Al-Si sample is subjected to microarc surface treatment, one part of the alloy becomes the oxide coating.

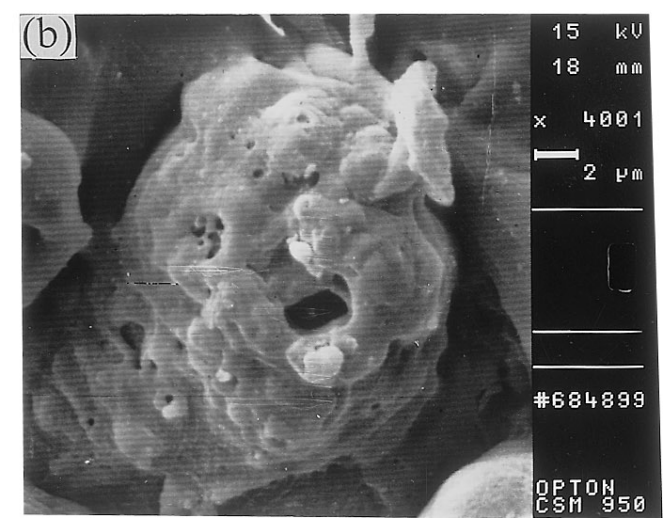

Fig. 2. Surface morphology of the MAO coating on ZL101 cast aluminum alloy. (b) is a magnified image of one grain. 

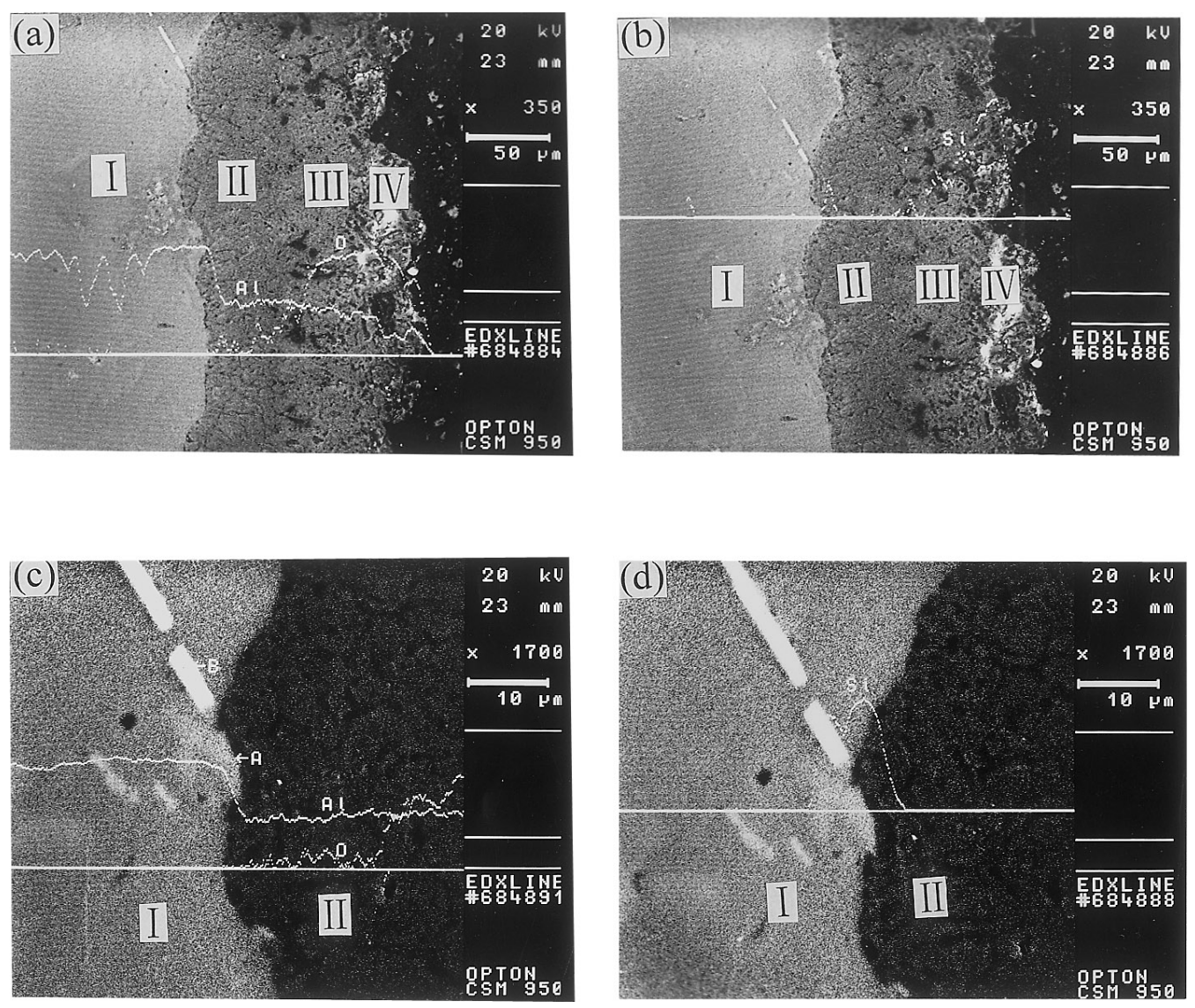

Fig. 3. SEM micrographs of a cross-section coated sample on ZL101 Al-Si alloy, I the alloy substrate, II the inner layer, III the intermediate layer, IV the surface layer. (c) and (d) are magnified images near the interface. (a), (c) $\mathrm{Al}$ and O line scan, (b), (d) Si line scan.

However, the presence of the elemental Si and needle-like particles near the coating/alloy interface confirms that the microstructure of the remained Al-Si alloy substrate has not been changed. In addition, the coating in Fig. 3(c) is much dark, which shows that the coating does not contain the elemental $\mathrm{Al}$, elemental $\mathrm{Si}$ and needle-like $\mathrm{FeSiAl}_{5}$ particles; the microarc discharge makes them melt and form complex oxide compounds.

\subsection{Phase Structure of the MAO Coating on Al-Si Alloy}

Figure 4(a) indicates that the Al-Si alloy is composed of $\mathrm{Al}$ and a little elemental Si phases. However, the phase containing impurity $\mathrm{Fe}$ is not detected due to its low content. The polished coating (Fig. 4(b)) corresponding to the inner layer consists of mullite $\left(3 \mathrm{Al}_{2} \mathrm{O}_{3} \cdot 2 \mathrm{SiO}_{2}\right), \alpha-\mathrm{Al}_{2} \mathrm{O}_{3}$ and $\gamma$ $\mathrm{Al}_{2} \mathrm{O}_{3}$ phases. The $\alpha-\mathrm{Al}_{2} \mathrm{O}_{3}$ and $\gamma-\mathrm{Al}_{2} \mathrm{O}_{3}$ fractions are almost equal. Furthermore, the diffraction peaks of $\mathrm{Al}$ phase in Fig. 4(b) are regarded coming from Al-Si substrate, because the oxide coating does not contain the elemental $\mathrm{Al}$ particles. On the other hand, the outer layer coating, including the surface and intermediate layers, contains a large amount of mullite, a little $\alpha-\mathrm{Al}_{2} \mathrm{O}_{3}$ and $\gamma-\mathrm{Al}_{2} \mathrm{O}_{3}$ phases (see Fig. 4(c)). By comparing the relative intensity of feature peaks of $\alpha-\mathrm{Al}_{2} \mathrm{O}_{3}\left(2 \theta=43.3^{\circ}\right)$ and $\gamma-\mathrm{Al}_{2} \mathrm{O}_{3}\left(2 \theta=45.9^{\circ}\right)$, it is found that the $\gamma-\mathrm{Al}_{2} \mathrm{O}_{3}$ phase fraction is much higher than $\alpha-\mathrm{Al}_{2} \mathrm{O}_{3}$ fraction in the outer layer. Analyzing the phase constituent of MAO coating on $\mathrm{Al}-\mathrm{Cu}$ alloy ${ }^{13)}$ proves that from the coating surface to the interior of the coating,

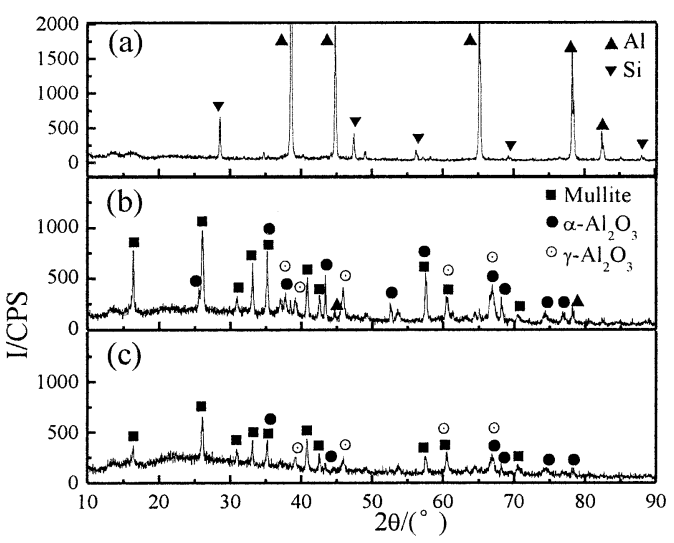

Fig. 4. XRD patterns of the MAO coatings on $\mathrm{Al}-\mathrm{Si}$ alloy formed in silicate solution. (a) alloy substrate, (b) the polished coating $(80 \mu \mathrm{m})$, (c) the unpolished coating (130 $\mu \mathrm{m})$.

$\alpha-\mathrm{Al}_{2} \mathrm{O}_{3}$ fraction gradually increases and $\gamma-\mathrm{Al}_{2} \mathrm{O}_{3}$ fraction correspondingly decreases. Figure 4 shows that the MAO coating on Al-Si cast alloy has a similar result. But the MAO coating on $\mathrm{Al}-\mathrm{Cu}$ alloy formed in silicate solution does not contain mullite phase or its fraction is very low. Hence, it is believed that Si component in Al-Si alloy substrate enhances mullite formation in the process of microarc oxidation.

Si line analysis in Fig. 3(b) shows that the Si content in the outer layer coating is very high. But XRD patterns in Fig. 4(c) indicate the mullite fraction in the outer layer is 
lower than in the inner layer. That suggests the outer layer coating on Al-Si alloy formed in silicate solution also contains lots of $\mathrm{SiO}_{2}$ amorphous phase besides mullite, $\alpha$ $\mathrm{Al}_{2} \mathrm{O}_{3}$ and $\gamma-\mathrm{Al}_{2} \mathrm{O}_{3}$. It is believed that the amorphous $\mathrm{SiO}_{2}$ is a main phase in the surface layer, because there is the highest Si content in this layer as shown in Fig. 3.

\subsection{Nanoindentation Test}

Figure 5 depicts that the distributions of hardness, $\mathrm{H}$, and elastic modulus, $\mathrm{E}$, in the MAO ceramic coating formed on ZL101 Al-Si alloy in silicate solution under the $50 \mathrm{mN}$ load. The curve profiles of $\mathrm{H}$ and $\mathrm{E}$ distributions are very similar. From the surface to the interior of the coating, the $\mathrm{H}$ and $\mathrm{E}$ increase gradually and reach maximum values in a distance of $20-50 \mu \mathrm{m}$ away from the coating/alloy interface. However, the $\mathrm{H}$ and $\mathrm{E}$ profiles have a transition zone near the interface.

Three steps in the $\mathrm{H}$ and $\mathrm{E}$ profiles imply that the coating has three layers, where their hardness and elastic modulus are much different. That is in good agreement with the cross-sectional micrograph shown in Fig. 3. The $\mathrm{H}$ and $\mathrm{E}$ in the inner layer coating of $70 \mu \mathrm{m}$ thick can reach about 15 $\mathrm{GPa}$ and $250 \mathrm{GPa}$, respectively, which are much higher than in the Al-Si substrate. In the region of 70-110 $\mu \mathrm{m}$ from the interface, it is so-called intermediate layer where the $\mathrm{H}$ and $\mathrm{E}$ are only about $9 \mathrm{GPa}$ and $130 \mathrm{GPa}$, respectively. On the other hand, for the surface layer corresponding to the region of $110-130 \mu \mathrm{m}$ from the interface, its hardness is similar to that in the alloy substrate. But its elastic modulus is only about $30 \mathrm{GPa}$, which is much lower than that in the alloy substrate.

By comparing with the XRD and EDS results, it is believed that the porous surface layer is mainly composed of amorphous $\mathrm{SiO}_{2}$ phase, thus its $\mathrm{H}$ and $\mathrm{E}$ are very low. The intermediate layer contains a large amount of mullite, $\alpha$ $\mathrm{Al}_{2} \mathrm{O}_{3}$ and $\gamma-\mathrm{Al}_{2} \mathrm{O}_{3}$ besides amorphous $\mathrm{SiO}_{2}$ phase. So this layer has higher $\mathrm{H}$ and $\mathrm{E}$. On the other hand, the $\mathrm{Si}$ content in the inner layer is lower, and the amorphous $\mathrm{SiO}_{2}$ is rarely formed. Hence, the inner layer has the highest $\mathrm{H}$ and $\mathrm{E}$ among the three layers due to the combination of hard $\alpha$ $\mathrm{Al}_{2} \mathrm{O}_{3}$ with relative soft $\gamma-\mathrm{Al}_{2} \mathrm{O}_{3}$ and mullite phases. In fact, the rough and porous surface layer of the MAO coating on $\mathrm{Al}-\mathrm{Si}$ cast alloy is very easy to be ground away, but the inner layer is rather hard and dense which has a higher wear resistance.

\section{Discussion}

As described in some papers, ${ }^{4,13-14)}$ under higher voltage, the dielectric breakdown takes place and many sparks or microarcs move quickly on the sample surface. Figure 6 depicts a schematic diagram of microarc discharge. The diameter of plasma discharge channel, estimated from residual discharge pore on the oxide coating surface, is in a range of $0.1-10 \mu \mathrm{m}$. Although the microarc or spark rapidly develops and extinguishes (with $10^{-4}-10^{-5} \mathrm{~S}$ ), the local instantaneous temperature and pressure inside the plasma discharge channels can reach $10^{3}-10^{4} \mathrm{~K}$ and $10^{2}-10^{3} \mathrm{MPa}$, respectively. ${ }^{15)}$ That is high enough to cause a plasma thermochemical reaction between substrate and electrolyte solution. Thus the coating near the discharge channel can be

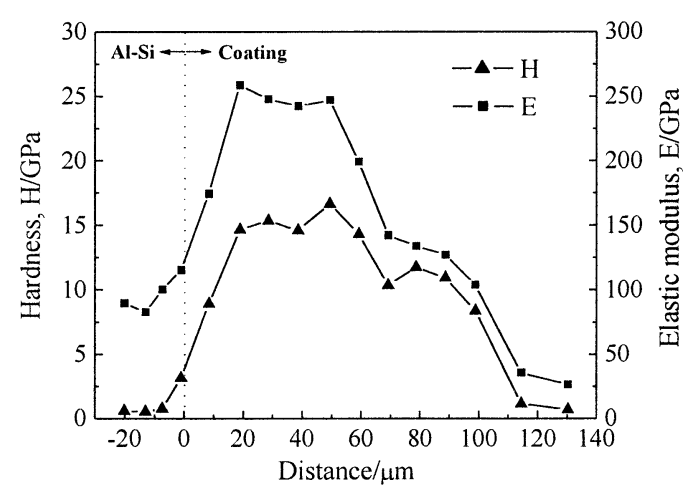

Fig. 5. Profiles of hardness, $H$, and elastic modulus, E, in the MAO coating on ZL101 Al-Si alloy.

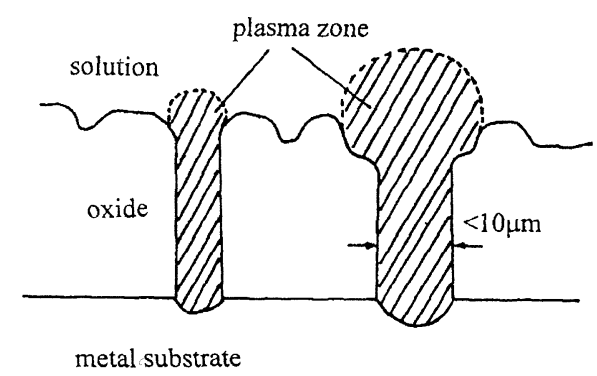

Fig. 6. Schematic diagram of microarc discharge in electrolyte solution.

melted, which is identified from the surface morphology of the coating in Fig. 2. While the microarc extinguishes, the melt rapidly solidifies to form mullite, $\alpha-\mathrm{Al}_{2} \mathrm{O}_{3}, \gamma-\mathrm{Al}_{2} \mathrm{O}_{3}$ and other oxide phases. Hence, the coating on Al-Si alloy has much high hardness and elastic modulus. Nevertheless, the critical cooling rate of forming amorphous phase is very low with only $2 \times 10^{-4} \mathrm{~K} / \mathrm{sec}$ for $\mathrm{SiO}_{2} \cdot{ }^{16)}$ So it is inevitable to form amorphous $\mathrm{SiO}_{2}$ phase in the outer layer coating on Al-Si alloy in silicate solution due to much high cooling rate near the electrolyte/coating interface. On the other hand, some Si atoms from both silicate electrolyte and $\mathrm{Al}-\mathrm{Si}$ alloy also react with $\mathrm{Al}$ and $\mathrm{O}$ atoms to synthesize mullite $\left(3 \mathrm{Al}_{2} \mathrm{O}_{3} \cdot 2 \mathrm{SiO}_{2}\right)$ phase in the interior of the coating, where the cooling rate of melt is lower than near the electrolyte/coating interface. That is in accordance with the results in Fig. 4.

\section{Conclusions}

(1) Microarc oxidation is a promising process for high silicon cast aluminum alloys. By this technique, a ceramic coating of $130 \mu \mathrm{m}$ thick can be prepared on ZL101 Al-Si alloy in silicate solution.

(2) This coating is composed of mullite, $\alpha-\mathrm{Al}_{2} \mathrm{O}_{3}, \gamma$ $\mathrm{Al}_{2} \mathrm{O}_{3}$ and amorphous $\mathrm{SiO}_{2}$ phases. From the surface to interior of the coating, $\alpha-\mathrm{Al}_{2} \mathrm{O}_{3}$ and mullite contents increase and $\gamma-\mathrm{Al}_{2} \mathrm{O}_{3}$ content decreases correspondingly. However, amorphous $\mathrm{SiO}_{2}$ is a main phase of the surface layer. The $\mathrm{Si}$ element has a gradient distribution in the coating, but the enriched $\mathrm{Si}$ in the surface and intermediate layers comes mainly from the electrolyte rather than the Al-Si alloy substrate. On the other hand, Si element in Al-Si alloy enhances the mullite formation in the coating.

(3) The profiles of hardness and elastic modulus are 
similar. From the surface to the inner layer, $\mathrm{H}$ and E gradually increase, though there are three steps related to three layers of the coating. The maximum $\mathrm{H}$ and $\mathrm{E}$ could reach about $15 \mathrm{GPa}$ and $250 \mathrm{GPa}$, respectively.

(4) The instantaneous high-temperature and high-pressure process in discharge channel makes the coating molten, but has no influence on the remained Al-Si alloy substrate. The microstructure of the remained substrate is not changed, even near the coating/alloy interface.

\section{Acknowledgments}

This research was sponsored by the national "863" hightech program of China (715-011-020), the national natural science foundation of China (59801003) and the new-star program of Beijing science and technology committee (9558102500). The authors wish to thank A/Prof. Hui Ma for assisting in the XRD test.

\section{REFERENCES}

1) A. L. Yerokhin, V. V. Lyubimov and R. V. Ashitkov: Ceram. Int., 24 (1998), 1.

2) X. Nie, A. Leyland, H. W. Song, A. L. Yerokhin, S. J. Dowey and A. Matthews: Surf. Coat. Technol., 116-119 (1999), 1055.
3) W. Xue, Z. Deng, R. Chen and T. Zhang: Surf. Eng., 16 (2000), 344.

4) W. Xue, C. Wang, Z. Deng and T. Zhang: ISIJ Int., 42 (2002), No. 6, 651.

5) W. Xue, C. Wang, Z. Deng, R. Chen and T. Zhang: J. Mater. Sci. Technol., 18 (2002), 37.

6) W. Xue, Z. Deng, T. Zhang, R. Chen and Y. Li: Rare Met. Mater. Eng., 28 (1999), 353.

7) S. V. Gnedenkov, P. S. Gordienko, S. L. Sinebrukhov, O. A. Khrisanphova and T. M. Skorobogatova: Corrosion, 56 (2000), 24.

8) J. Schreckenbach, F. Schlottig, G. Marx, W. M. Kriven, O. O. Popoola, M. H. Jilavi and S. D. Brown: J. Mater. Res., 13 (1999), 1437.

9) V. I. Belevantsev, O. P. Terleeva, G. A. Markov, E. K. Shulepko, A. I. Slonova and V. V. Utkin: Prot. Met., 34 (1998), 416.

10) G. A. Markov, A. I. Slonova and O. P. Terleeva: Prot. Met., 33 (1997), 257.

11) A. I. Slonova, O. P. Terleeva and G. A. Markov: Prot. Met., 33 (1997), 183.

12) A. V. Timoshenko and Yu. V. Magurova: Prot. Met., 31 (1995), 474.

13) W. Xue, Z. Deng, Y. Lai and R. Chen: J. Am. Ceram. Soc., 81 (1998), 1365 .

14) W. Xue, Z. Deng, R. Chen and T. Zhang: Thin Solid Films, 372 (2000), 114.

15) M. D. Klapkiv: Mater. Sci., 31 (1995), 494.

16) G. Qiu and L. Huang: Formation of Glasses (in Chinese), Ordnance Industry Press, Beijing, (1987), 180. 